\title{
La conciliación prejudicial administrativa como requisito de procedibilidad en la jurisdicción administrativa*
}

\author{
Gloria Milena Torres Rojas* \\ Recibido: 6 de febrero de 20176 • Aprobado: 20 de mayo de 2017
}

\section{Resumen}

Se afirma que la conciliación prejudicial es una institución que ha cobrado relevancia en nuestro país como mecanismo para: i) descongestionar los estrados judiciales; ii) reprimir la carga que tienen los jueces; iii) básicamente cumplir con los principios de justicia, basado en la celeridad, efectividad y economía procesal (Bermejo, 2015). Empero, Peña (2014) hace una reflexión que revela un panorama distinto, según el cual:

El acuerdo con las cifras del Consejo Superior de la Judicatura, en 2013 el total de inventario inicial fue de 2295.873 procesos, los ingresos efectivos fueron $2^{\prime} 656.779$, los egresos efectivos $2^{\prime} 646.903$, lo que da un acumulado de $2^{\prime} 305.749$ que representa la congestión inicial para 2014 (p. 6).

Palabras claves: conciliación extrajudicial, requisito de procedibilidad, mecanismo alternativo de solución de conflictos.

"El artículo es producto del proyecto de investigación de la tesis doctoral titulada: Medios alternativos de solución de conflictos distintos al uso de la fuerza para resolver la crisis Norcoreana, gestionado en Xiamen University Law School, China. DOI: http://dx.doi.org/10.15332/s1900-0448.2017.0047.05

*" Magíster en Análisis de Problemas Políticos, Económicos e Internacionales de la Universidad Externado de Colombia. Bogotá, Colombia. Estudiante de Doctorado de Xiamen University, China. Correo electrónico: gloriamile24@yahoo.it 


\title{
The Administrative Conciliation as a Procedure Requirement in the Administrative Jurisdiction
}

\begin{abstract}
It has been said that prejudicial conciliation is an institution that has gained relevance in Colombia as a mechanism to i) decongest judicial offices, ii) reduce the burden of judges, iii) accomplish with the principles of justice, celerity, effectivity and economy (Bermejo, 2015). However, the reflection of Peña (Peña, 2014) reflects the opposite.
\end{abstract}

According with data from Consejo Superior de la Judicatura, in 2013 there were 2.295.873 judicial cases, the amount of cases that were brought to justice were 2.656.779 and those who were solved were 2.646.903. As a result, 2.305.749 represents the initial congestion for 2014.

Keywords: Administrative conciliation, Requirement of procedure, Due process, Administration of justice.

\section{A CONCILIAÇÃo PRÉ-JUdicial ADMinistrativa COMO REQUiSito DE PROCEDIBILIDADE NA JURISDIÇÃO ADMINISTRATIVA.}

\section{Resumo}

Afirma-se que a conciliação pré-judicial é uma instituição que tem adquirido relevância em nosso país como mecanismo para: i) descongestionar os tribunais judiciais; ii) reprimir a carga que tem os juízes; iii) basicamente cumprir com os princípios de justiça, baseado na cerelidade, efetividade e economia processual (Bermejo, 2015) Porém, Peña (2014) faz uma reflexão que revela um panorama diferente, segundo a qual:

O acordo com as cifras do Conselho Superior da Judicatura, em 2013 o total de inventario inicial foi de $2{ }^{\prime} 295.873$ processos, os ingressos efetivos foram 2’656.779, os egressos efetivos $2^{\prime} 646.903$, o que dá um acumulado de 2’305.749 que representa a congestão inicial para 2014 (p. 6).

Palavras-chave: conciliação extrajudicial, requisito de procedibilidade, mecanismo alternativo de solução de conflitos. 


\section{Introducción}

Mientras en Colombia se siga avanzando por el camino del desconocimiento de los derechos constitucionales, desarrollándolos bajo parámetros de lucro y bajo relaciones utilitaristas que privilegien intereses de los sectores más poderosos en franco detrimento de los derechos de las mayorías, mientras se sigan generando políticas públicas que tiendan a profundizar estas estructuras de inequidades e injusticias, mayor será la responsabilidad como profesionales del derecho en analizar estas problemáticas (Saidiza y Carvajal, 2016, p. 15).

Con la implantación legal de la figura de la conciliación extrajudicial como requisito de procedibilidad en asuntos contencioso administrativos, surge la necesidad de establecer si la misma tiene o no las bondades que se pregonan en su favor, particularmente según las citas de sus principales defensores; por tanto el problema a abordar se refiere a establecer las consecuencias que tiene la conciliación prejudicial como requisito de procedibilidad en el medio de control de nulidad y restablecimiento del derecho, que se plantea así: ¿Qué consecuencias tiene para el derecho a acceder a la administración de justicia la conciliación extrajudicial como requisito de procedibilidad en el medio de control de nulidad y restablecimiento del derecho?

Ante la anterior pregunta, el objetivo primordial del presente artículo radica en demostrar, de manera particular, si la conciliación contribuye o no a descongestionar los despachos judiciales y, por otra parte, si realmente cumple con principios de justicia y economía procesal.

La hipótesis, en consonancia con la anterior cuestión, es demostrar que la conciliación administrativa prejudicial en el medio de control de nulidad y restablecimiento del derecho, contrario a la consideración del legislador en materia administrativa, no es un mecanismo idóneo ni eficaz para garantizar derechos fundamentales, tales como el acceso a la administración de justicia y el debido proceso, como tampoco para descongestionar los despachos judiciales.

\section{Metodología}

El método empleado es el deductivo, porque parte de lo general (la conciliación administrativa en el medio de control de nulidad y restablecimiento del derecho), aplicándose a casos concretos para establecer los límites de esta institución; 
analizando, a manera de ejemplo, un caso en que se desconoció el acceso a la administración de justicia, al debido proceso y la equidad.

A la vez se utiliza la índole explicativa, dado que se hacen críticas a la institución de la conciliación extrajudicial, al evidenciar que lejos de contribuir a la descongestión judicial, contribuye, contrario sensu, a su congestión. El enfoque de la investigación es mixto, por tener tanto elementos cualitativos como cuantitativos. Cualitativos, porque analiza heurísticamente la institución jurídica de la conciliación administrativa en el medio de control de nulidad y restablecimiento del derecho para demostrar sus efectos en la descongestión judicial y en el debido proceso; cuantitativos porque se soporta en estadísticas para demostrar la hipótesis, esta, en consonancia con la anterior cuestión, es demostrar que la conciliación administrativa prejudicial en el medio de control de nulidad y restablecimiento del derecho, contrario a la consideración del legislador en materia administrativa, no es un mecanismo idóneo ni eficaz para garantizar derechos fundamentales, tales como el acceso a la administración de justicia y el debido proceso, como tampoco para descongestionar los despachos judiciales. De tal manera que, para dar respuesta a la pregunta planteada ut supra, este artículo desarrolla la siguiente estructura:

En primer lugar, es necesario definir la institución de la conciliación y sus clases, enfatizando en el examen de la conciliación prejudicial administrativa y sus características, centrada en la exigencia legal como requisito de procedibilidad en el medio de control de nulidad y restablecimiento del derecho, abordando las variables de acceso a la administración de justicia y congestión judicial en Colombia. En segundo término, es preciso examinar cada una de las razones por las que se afirma que la conciliación no es idónea, abordando los siguientes tópicos: i) Los acuerdos conciliatorios son ínfimos; ii) los límites de la conciliación para acceder a la administración de justicia; iii) problemas de la congestión judicial. Después de ello se establecerá por qué, contrario a la visión del legislador colombiano, iv) la conciliación es ineficaz, cuando por regla general no descongestiona despachos judiciales, y, más grave aún; v) conculca derechos fundamentales como el debido proceso, por medio de los efectos de la conciliación y, finalmente; vi) se expondrán las conclusiones del trabajo.

Para ilustrar lo anterior se citará, como ejemplo, la experiencia judicial en las que se advierte cómo la conciliación prejudicial administrativa obstaculiza el efectivo acceso a la administración de justicia, y cómo bajo sus banderas, en cambio, se han conculcado caros derechos fundamentales, para llegar a la conclusión de cuál es realmente el impacto de la conciliación administrativa prejudicial. 


\section{La conciliación}

La expresión conciliación proviene del latín conciliatio y en su formulación verbal conciliare. En su acepción general significa acción y efecto de conciliar, conformidad o semejanza de una cosa con otra (Casares, 2012).

Couture (1960), define la conciliación como: "el acuerdo o aveniencia de partes que, mediante renuncia, allanamiento o transacción, hacen innecesario el litigio pendiente o evitan el litigio eventual" (p. 27).

Por su parte, el artículo 64 de la Ley 446 de 1998 define la conciliación como: "un mecanismo de resolución de conflictos, a través del cual, dos o más personas gestionan por sí mismas la solución de sus diferencias, con la ayuda de un tercero neutral y calificado, llamado el conciliador".

La jurisprudencia (1999), por su parte, define la conciliación como:

Una institución en virtud de la cual se persigue un interés público, mediante la solución negociada de un conflicto jurídico entre las partes, con la intervención de un funcionario estatal perteneciente a la rama judicial o a la administrativa, y excepcionalmente de particulares (Corte Constitucional de Colombia, Sentencia C-160/99).

La Corte Constitucional (1996) la definió como:

Un medio no judicial de resolución de conflictos, mediante el cual las partes, entre quienes existe una diferencia susceptible de transacción, con la presencia activa de un tercero conciliador, objetivo e imparcial, buscan la forma de encontrar solución y superar el conflicto de intereses existente (Corte Constitucional de Colombia, Sentencia C-226/93).

Por su parte, en la Sentencia C-222 de 2013 se define así:

Procedimiento por el cual un número determinado de individuos, trabados entre sí, por causa de una controversia jurídica, se reúnen para componerla, con la intervención de un tercero neutral -el conciliador- quien, además de proponer fórmulas de acuerdo, da fe de la decisión de arreglo e imparte su aprobación (2013).

El Consejo de Estado define la conciliación como: 
La concreción de una filosofía de diálogo, concertación y solución civilizada de conflictos, fruto del avenimiento y la concordia de las partes, que implica de suyo el reconocimiento del otro como forma del accionar social, dando origen a la verdad jurídica por consenso (1999).

La Ley 640 de 2001 en su artículo 1 establece que la conciliación tiene dos sentidos según su contexto: uno procedimental y otro sustancial. En relación con su acepción procedimental, dice que la conciliación es:

Un mecanismo de resolución de conflictos a través del cual, dos o más personas gestionan por sí mismas la solución de sus diferencias, con la ayuda de un tercero neutral y calificado denominado conciliador. Según esta acepción, la conciliación es apenas una serie de pasos preestablecidos que tiene por objeto la celebración de un acuerdo entre dos o más personas. No obstante, el término conciliación, también se refiere al acuerdo al que se llega mediante la celebración del procedimiento conciliatorio. En este segundo sentido sustancial, la conciliación se materializa en un acta que consigna el acuerdo al que llegan las partes (2001).

Para efectos de este artículo se tendrá en cuenta el concepto de Peña (2014), para quien "la conciliación es entendida como la conciliación prejudicial creada en la Ley 23 de 1991 operada por particulares, diferente a la conciliación judicial” (p. 6).

\section{Clases de conciliación}

La conciliación se puede clasificar doctrinaria y jurisprudencialmente en: i) extrajudicial; ii) judicial y iii) prejudicial.

La conciliación extrajudicial es aquella que se tramita antes de la iniciación del proceso en la jurisdicción de lo contencioso administrativo, y por fuera de iniciar la acción correspondiente (Cerra, 2011). Por su parte, la judicial se presenta dentro del trámite del proceso contencioso- administrativo de reparación directa o de controversia contractual en presencia de un conciliador, que en este caso es cualificado y es el magistrado sustanciador del proceso (Cerra, 2011). La conciliación prejudicial es la que se intenta antes de iniciar un proceso judicial (Berlín, 1999). Agregándose la particularidad que le ha señalado el legislador, como requisito previo a la acción judicial administrativa. 


\section{Conciliación en materia contencioso-administrativa}

La conciliación prejudicial en asuntos contencioso-administrativos, según lo contemplado en la Ley 1437:

Es un mecanismo alternativo de solución de conflictos, que constituye, a la vez, por mandato legal, requisito de procedibilidad para el ejercicio de los medios de control consagrados en los artículos 138, 140 y 141, en concordancia con el numeral primero del artículo 161 del Código de Procedimiento Administrativo y de lo Contencioso Administrativo (2011).

A partir de la vigencia de la Ley 1285 de 2009, cuando los asuntos sean conciliables, siempre constituirá requisito de procedibilidad de las acciones previstas en los artículos 85, 86 y 87 del Código Contencioso Administrativo, el adelantamiento del trámite de la conciliación extrajudicial.

Las acciones en derecho administrativo son: la de nulidad simple, reparación directa, contractual, ejecutiva, repetición, nulidad y restablecimiento del derecho, lesividad, nulidad de cartas de naturaleza electoral (García, 2008). No admiten conciliación las acciones de nulidad simple, nulidad de cartas de naturaleza y electoral; pues estas, según sostiene García (2008), materializan criterios de pura legalidad, razón por la que no admiten conciliación. De las demás, dice: "algunas sintetizan solo patrimonialidad como las de reparación directa, contractual, ejecutiva y repetición, las otras contienen los dos conceptos de legalidad y patrimonialidad a la vez, las cuales son nulidad y restablecimiento del derecho y lesividad, siendo todas conciliables" (p. 175).

Como argumenta Bermejo (2015), es preciso tener en cuenta que:

Con el artículo 13 de la Ley 1285 de 2009, quedó en firme la índole obligatoria del agotamiento de la conciliación para acceder a la jurisdicción contenciosa administrativa, de manera que se entenderá cumplido este requisito cuando: por una parte, se efectúe la audiencia de conciliación sin que se logre acuerdo; o cuando vencido el término previsto, es decir, tres (3) meses, contados a partir de la presentación de la solicitud, la audiencia no se hubiere celebrado por cualquier causa (p. 119). 


\section{La conciliación prejudicial}

Doctrinaria y jurisprudencialmente se ha recalcado la relevancia de la institución de la conciliación prejudicial como mecanismo contra la congestión judicial, es así como González (2010), Henao (1996), Hoyos (2005), Hernández (2005) y Giraldo (2004) destacan que:

La conciliación contribuye a mejorar la eficacia y eficiencia. De igual forma se aduce que entre las ventajas más importantes de la conciliación contencioso-administrativa están la pronta efectividad de los derechos de los administrados, el ahorro patrimonial del Estado, la protección efectiva de los derechos de los administrados, evitar la incertidumbre jurídica y la congestión de la jurisdicción (p. 57).

No obstante, esas bondades que se predican de la conciliación prejudicial administrativa, la realidad actual, caracterizada por un gran número de procesos en la jurisdicción administrativa, aunada a la vulneración de derechos fundamentales, como lo constituye el efectivo acceso a la administración de justicia, hacen cuestionarse sobre si realmente la conciliación ha sido verdaderamente eficaz y si la misma guarda armonía con los propósitos que guiaron su instauración legal.

Frente al primer propósito del legislador con la introducción de la conciliación como mecanismo de solución de conflictos, se tienen cifras que contradicen su conveniencia, cuando, por el contrario se afirma que la congestión judicial no se ha reducido porque:

De acuerdo con las cifras del Consejo Superior de la Judicatura, en el 2013 el total de inventario inicial fue de $2 ` 295.873$ procesos, los ingresos efectivos fueron 2’656.779, los egresos efectivos 2‘646.903, lo que da un acumulado de 2‘305.749 que representa la congestión inicial para 2014 (Peña, 2014).

De tal modo que, entre las razones que justifican este artículo están establecer los límites de la conciliación prejudicial y la eficacia o ineficacia de la misma, aspectos de gran relevancia para que el legislador examine si debe continuar exigiendo o no este mecanismo de solución de conflictos como imperativo para acceder a la jurisdicción contencioso-administrativa, o si, por el contrario, se debe replantear esta institución para que no sea exigible en esta jurisdicción, a través los jueces de instancia como requisito de procedibilidad si resulta ineficaz para ello. 
Es imperativo que la ciudadanía, de acuerdo con el derecho de publicidad e información, sepa si con ella se ha logrado o no la pronta efectividad de los derechos de los administrados y, consecuencialmente, se establezca si se ha obtenido o no la eficacia y eficiencia del aparato judicial en la solución de conflictos, aspecto trascendental, no solo para la jurisdicción de lo contencioso-administrativo sino, también, transversalmente, para quienes acuden al aparato jurisdiccional del Estado para hacer efectivos sus derechos.

Conciliación en la acción de nulidad y restablecimiento del derecho

La acción de nulidad y restablecimiento del derecho sí es conciliable, tal como lo reconoció el Consejo de Estado en 2012 al manifestar que:

Podrán conciliar, total o parcialmente, en las etapas prejudicial o judicial, las personas jurídicas de derecho público a través de sus representantes legales o por conducto de apoderados, sobre conflictos de carácter particular y contenido económico, a través de las acciones previstas en los artículos 85, 86 y 87 del CCA.

Si bien es cierta la exigencia de la conciliación prejudicial en la citada acción, es preciso establecer cómo la misma no ha sido idónea para alcanzar los propósitos para los que fue creada. Ello se ha podido establecer en la acción de Nulidad y restablecimiento, por cuanto no ha cumplido los propósitos para los que fue creada, como se expresa en los siguientes puntos.

\section{Los acuerdos conciliatorios son ínfimos}

Son pocas las solicitudes que terminan en acuerdo entre las partes, lo anterior se corrobora con cifras de la misma Procuraduría General de la Nación, obtenidas por la autora de este proyecto, por medio de un derecho de petición que demandaba información sobre las solicitudes de conciliación en el medio de control de nulidad y restablecimiento del derecho que han terminado con y sin acuerdo en los años 2013, 2014 y 2015, información que arrojan cifras corroborando que la conciliación no ha cumplido sus objetivos.

En el año 2013 solo se lograron a nivel nacional 5.463 acuerdos de conciliación frente a 51.354 solicitudes en las que no se logró ningún acuerdo. En el año 2014 si bien es cierto hubo 10.676 acuerdos conciliatorios, esta cifra es exigua si se compara con las solicitudes en las que no se obtuvo ningún acuerdo, que en el 2014 fueron 
de 54.103, y en el año 2015 los acuerdos conciliatorios alcanzados fueron de 6.803, frente a 43.203 solicitudes sin acuerdo conciliatorio (Procuraduría General de la Nación, 2016). Cifras estas que sustentan la hipótesis de este trabajo, es decir, de que la conciliación en la acción de nulidad y restablecimiento del derecho no es un mecanismo idóneo, porque si fuera verdad que la conciliación coadyuva a que las partes encuentren una solución a sus diferencias, entonces cómo se explica el gran número de solicitudes en las que no se obtiene ningún tipo de acuerdo; por tanto, no son claras las razones por las cuales no se llega a un acuerdo conciliatorio, como argumenta Guerra (2014): "quizás sea por causas normativas o de actitud entre las partes, ya que se sostiene que a los servidores públicos no les gusta conciliar, por temor a comprometer recursos del erario, y prefieren mejor que el juez emita sentencia" (p. 23).

Lo anterior, sugiere que "la reciente puesta en vigencia de la conciliación como requisito de procedibilidad, haya sido recibida con escepticismo por muchos sectores, ya que ha implicado, desde la perspectiva jurídica, más preguntas que respuestas, más dudas que conclusiones" (Guerra, 2014).

Por lo tanto, es menester examinar más adelante el impacto de la conciliación en la descongestión judicial en el debido proceso y en la justicia.

\section{Límites de la conciliación para acceder a la administración de justicia}

La jurisprudencia de la Corte Constitucional define el derecho constitucional de acceso a la administración de justicia como:

Un derecho medular, es decir como la garantía real y efectiva que el Estado le ofrece al individuo, de poder acudir, para resolver las controversias que surjan con otros individuos u organizaciones y con el mismo Estado, ante un juez, con miras a obtener una resolución motivada, ajustada a derecho, y dictada de conformidad con el procedimiento y las garantías constitucionales previstas en la Constitución y en la ley (Corte Constitucional de Colombia, Sentencia T-476/98).

Existen dos sentidos del concepto del derecho de acceso a la administración de justicia. En sentido amplio, como indica Toscano (2013): 
El derecho a acceder a la administración de justicia permite al que se considera con algún derecho a acudir a un órgano imparcial del Estado, que le atienda, verifique si su razón procede, para que se le haga efectivo. Por ello, no se agota en el acceso a los jueces y tribunales, ni en tramitar ante estos sus pretensiones, ni se limita a garantizar la obtención de una resolución de fondo. Exige también que el fallo judicial se cumpla y que el recurrente sea repuesto en su derecho y compensado. Con respecto al sentido restringido del término, consiste en un derecho fundamental universal, que protege el que todas las situaciones jurídicas puedan ser sometidas a un proceso judicial y que en el mismo los tribunales actúen perfectamente (p. 7).

\section{Según lo establece la Corte Constitucional (1999):}

El acceso a la justicia comporta no solo la posibilidad de que cualquier persona solicite protección de sus derechos, sino también, por expresa resolución del artículo 116 constitucional, que pueda resolver sus disputas a través de mecanismos como la conciliación (C-163).

No obstante, como lo advierte la Corte (1999):

Un razonable diseño normativo que promueva la intervención de los particulares en la resolución pacífica y negociada de los conflictos jurídicos, no puede desplazar de manera definitiva a la justicia estatal formal ni puede constituirse en un obstáculo que impida el acceso a ella (Corte Constitucional de Colombia, Sentencia C-160).

Este punto es importante para efectos de este trabajo, ya que en ciertos casos los requisitos de procedibilidad como la conciliación pueden constituirse en límites al derecho de acceder a la administración de justicia, como cuando los operadores jurídicos no guían sus fallos de acuerdo con lo dispuesto en el artículo 228 de la Constitución que ordena que en las decisiones judiciales prevalecerá el derecho sustancial; siendo así como algunos tribunales conculcan el citado acceso a la administración de justicia esgrimiendo que no se agotó el requisito de procedibilidad de todos los actos administrativos, viciados de nulidad y, soslayando que este requisito puede subsanarse en el trámite del proceso judicial y, abiertamente se viola el acceso a la administración de justicia cuando se demuestra que el citado requisito de procedibilidad de la conciliación fue ejecutado durante el trámite del 
proceso judicial, por lo cual, si no se agotó la conciliación previamente, se convalida efectivamente dicho requisito, sin que se vulneren derechos sustanciales.

Asimismo, es necesario que se haga efectiva la publicidad de los datos estadísticos de la Procuraduría General de la Nación y del Consejo Superior de la Judicatura ante la precariedad de favorabilidad que se evidencia a través de los resultados de la conciliación como requisito de procedibilidad administrativa del proceso de nulidad y restablecimiento del derecho, para que se puedan cumplir materialmente los derechos que se derivan de la misma, mediante la participación ciudadana, porque en este caso, como lo expresó la Sentencia C-274 de 2013:

Este mecanismo es la condición esencial del funcionamiento adecuado de la democracia y del Estado de derecho... La publicidad de las funciones públicas (C.P., art. 209), es la condición esencial del funcionamiento adecuado de la democracia y del Estado de derecho; sin ella, sus instituciones mutan de naturaleza y dejan de existir como tales. Este derecho entonces constituye una garantía que materializa el principio de democracia participativa sobre el cual se estructura el Estado colombiano, que a su turno fortalece el ejercicio de la ciudadanía, en tanto permite formar un ciudadano activo, deliberante, autónomo y crítico que pueda ejercer un debido control de la actividad del Estado. (ii) En segundo lugar, el acceso a la información pública cumple una función instrumental para el ejercicio de otros derechos constitucionales, ya que permite conocer las condiciones necesarias para su realización. Así por ejemplo, en relación con los derechos de las víctimas, esta corporación reconoció que el derecho a acceder a documentos públicos es una herramienta esencial para la satisfacción del derecho a la verdad de las víctimas de actuaciones arbitrarias y de violaciones de derechos humanos y para garantizar el derecho a la memoria histórica de la sociedad (2013).

De ahí que el legislador está en mora de abolir un requisito legal de procedibilidad que, a la vez que inoperante, da espacio para la arbitrariedad a los operadores judiciales, sin que los conciliadores, en la gran mayoría de los casos, cumplan efectivamente su rol de mediadores, ora por temor a comprometer el erario público, ora por falta de idoneidad para el mismo, sin que se dé información por parte de la administración, mediante la debida publicación a los administrados; tornándose, de tal modo, nugatoria la participación ciudadana para reclamar sus derechos mediante el control efectivo de los actos de la administración, en el caso que se examina, por ejemplo, presentar iniciativas legislativas que eliminen esa exigencia 
de la conciliación previa por ser obsoleta e inoperante, a la vez que representa un mecanismo de manipulación perverso por algunos operadores judiciales como se ha ocurrido en tantos procesos administrativos, en los que los derechos fundamentales de los administrados han resultado nugatorios, vulnerándose con ello el efectivo acceso a la administración de justicia.

\section{Problemas de congestión judicial}

Para discutir este tema es necesario conocer a fondo el problema, y para ello es menester hacer un enfoque desde las ambiguas direcciones que informan la congestión judicial al día de hoy. Cabe aclarar que la congestión judicial va dirigida hacia dos puntos centrales: el primero hacia las instituciones judiciales, encargadas del poder judicial, y el segundo hacia todos los habitantes del país, cuando este derecho fundamental y servicio público esencial se ve vulnerado por diferentes factores sociales, personales y económicos, entre otros. Según estudios realizados por diferentes asociaciones, sociedades y empresas, con el objetivo de fijar cifras y estadísticas, se encuentra que uno de los mayores problemas que hoy en día provoca la congestión judicial es "la demanda que ha crecido cerca de $300 \%$ mientras la oferta de funcionarios de la rama solo ha llegado al $20 \%$ ” (CSJ, 2013).

Así mismo, para poder explicar las causas del problema descrito, es necesario hacer remisión al Informe de Gestión 2013-2014 Sala Administrativa Consejo Superior de la Judicatura, el cual se encarga de fijar las funciones de cada uno de los órganos judiciales del Estado y plantea las contrariedades de forma porcentual y de gestión. Enseguida se incluye el informe de gestión de los años 2013-2014, para verificar por medio de preguntas puntuales las problemáticas de la rama judicial, como sigue:

¿Qué problemáticas tiene la rama judicial?: desde 1993 hasta 2013, la población colombiana creció un $30 \%$, pero la tasa de cobertura de los despachos judiciales por cada 100.000 habitantes, disminuyó de 10.9 a 10.5 despachos permanentes. De estos datos se infiere que no hay suficiente recurso físico para la demanda de justicia. No obstante ese escenario, en el mismo periodo, la solicitud de servicios de justicia ha tenido un aumento en la demanda del $303 \%$. Sin embargo, el número de funcionarios y empleados judiciales solo ha crecido un $24 \%$, lo que dificulta la prestación del servicio de justicia en el país. 
¿Cuántas demandas de justicia se recibieron en el 2013?: el año pasado la rama judicial recibió 3’012.046 demandas de justicia. Los despachos judiciales gestionaron 3’272.608 procesos. Esta es la labor realizada en 6.029 despachos judiciales del país, de los cuales 4.878 son permanentes y 1.151 son de descongestión. Particularmente a la jurisdicción ordinaria ingresaron 2’151.904 procesos en el 2013.

¿Cuántos procesos se evacuaron?: respecto a egresos efectivos (procesos que logran terminar y no pasan de una dependencia a otra), la cifra llegó a 2`646.903 procesos evacuados al concluir el 2013, de los 2’656.779 ingresos efectivos de 2013.

¿Cuál fue la productividad en la evacuación de procesos?: la productividad anual efectiva fue de $99.6 \%$ en la gestión de procesos. Al concluir el 2013, el inventario registró una disminución de 16 \% (CSJ, 2013).

De lo citado anteriormente, es posible inferir que en Colombia no existen los suficientes recursos físicos para la demanda de justicia, puesto que en el último año la solicitud de servicios de justicia ha tenido un aumento en la demanda del 303 $\%$, y sin relación alguna, el número de funcionarios y empleados judiciales solo ha crecido un $24 \%$, lo que dificulta la prestación del servicio de justicia en el país, que se traduce en congestión judicial.

Igualmente, una de las principales causas de la congestión judicial radica en la ineficacia del accionar el aparato judicial con los mal llamados "procesos o casos inoficiosos", es decir, aquellos conflictos sociales que demandan el aparato judicial y que podrían tener una solución pacífica por parte de los funcionarios que conocen de dichos conflictos.

\section{Ineficacia de la conciliación prejudicial: no idoneidad de la institución}

Visto el problema de la congestión judicial, ahora es necesario acotar que la figura de la conciliación administrativa presenta una serie de problemas, como los que veremos a continuación.

\section{La conciliación prejudicial no descongestiona despachos judiciales}

En primer término, estadísticamente, la conciliación administrativa como requisito de procedibilidad no ha disminuido la congestión judicial, ya que de 
acuerdo con cifras de la Procuraduría General de la Nación, según Díaz y García (2014), "el ingreso de procesos judiciales a la jurisdicción contenciosa aumentó considerablemente, ya que dicho ingreso pasó de 67.762 procesos en el 2009 a 163.256 en el 2012".

Además de tales cifras, se debe considerar también que, según las Estadísticas del Sistema de Información de la Rama Judicial, la conciliación no ha disminuido la congestión judicial; de hecho, en sus últimos proyectos de descongestión judicial, el Consejo Superior de la Judicatura no ha utilizado la conciliación como mecanismo para disminuir la carga de los jueces, lo que ha hecho es crear despachos de descongestión judicial, pues como observa Peña (2014), "la conciliación no descongestiona, quien lo hace es el juzgado de descongestión”.

\section{La conciliación prejudicial conculca derechos fundamentales como el debido proceso, el trabajo e igualdad}

Existen varias experiencias judiciales en las que se advierten cómo se ha obstaculizado el efectivo acceso a la administración de justicia y se han conculcado caros derechos fundamentales como el del debido proceso, el trabajo y la igualdad $y$, primordialmente, la dignidad humana, por privilegiar los intereses particulares a través de una institución estatal, que lejos de contribuir a la solución pacífica de conflictos, lo que genera es escepticismo y decepción entre los ciudadanos quienes ven frustradas sus legítimas aspiraciones, en virtud de que se privilegian las meras formalidades sobre el derecho sustantivo para la consecución de fines ilegítimos, resultado evidente la falta de garantías para la parte más vulnerable (el administrado) en situaciones como estas, como por ejemplo el caso del expediente 4202-02 de 2003, en el que se pretendió determinar si se ajustó a la legalidad el acta del 5 de febrero de 2000, por medio de la cual la Comisión Evaluadora del Concurso Público, convocada por la Universidad de Sucre para proveer dos plazas en el área de educación matemática, estableció la lista de elegibles al cargo de profesor de tiempo completo en el área de matemáticas, ubicando a la demandante en el tercer lugar, motivo por el cual no fue designada en el empleo respectivo.

Frente a este caso el Consejo de Estado confirmó la decisión del Tribunal que se declaró inhibido para desatar la litis por no haberse efectuado la conciliación del acto administrativo del nombramiento de los demás docentes, desconociéndose igualmente, en este caso, los derechos de acceso a la administración de justicia como la prevalencia del derecho sustancial sobre el meramente formal, sin que se hubiese 
hecho, al menos, un test de ponderación sobre la prevalencia de los derechos fundamentales en tensión, esgrimiendo, únicamente, que no se agotó la conciliación del acto administrativo subsiguiente al de la conformación de la lista de elegibles, solo por estar establecido como requisito previo al acceso a la jurisdicción especial administrativa, sin atender los principios y valores consagrados en la carta.

\section{Efectos de la conciliación en la descongestión judicial}

Ahora, es menester examinar los efectos de la conciliación administrativa en la descongestión judicial, para ello es necesario mencionar a que "si lo que se trata es de descongestionar despachos la realidad es otra, ya que son pocos los asuntos que finiquitan con acuerdo en las procuradurías delegadas" (Guerra, 2014, p. 6).

Y, como prueba de ello están las cifras de la Procuraduría General de la Nación, donde se muestra que a pesar de que en el año 2009 se expidió la Ley 1285, la que estableció la conciliación como requisito de procedibilidad en aras de disminuir la congestión judicial e incentivar la solución de controversias de manera pacífica,

Las estadísticas demuestran que durante el primer año de implementación de la conciliación, esta ha sido poco útil a la luz de su propósito. En efecto, las solicitudes de conciliación se dispararon en un $806 \%$ en el 2009, pero no se registra una variación significativa en el número de acuerdos conciliatorios logrados. La cifra asciende a 2.565 acuerdos en el 2008, a 2.855 en el 2009, un incremento de tan solo $11.3 \%$, que contrasta con la enorme variación porcentual de solicitudes. En suma, los resultados de la conciliación como requisito de procedibilidad en materia contenciosa administrativa, han sido insuficientes (Justicia, 2010).

Otros datos que demuestran la ineficacia de la conciliación previa son los proporcionados por la Procuraduría General de la Nación por medio de un Derecho de Petición, estos datos proporcionados por esta institución muestran, por ejemplo, que en el año 2012 solo hubo a nivel nacional 3.389 solicitudes con acuerdo, mientras que hubo un total de 42.991 solicitudes sin acuerdo conciliatorio. En el año 2013, de las 63.291 solicitudes radicadas hubo 51.354 solicitudes sin acuerdo, mientras que tan solo se obtuvo acuerdo en 5.463. 
A la misma conclusión llegan Díaz y García, en la revista Con-texto de la Universidad Externado de Colombia, quien demuestra por medio de datos proporcionados por la Procuraduría que:

En promedio, entre los años 2004 y 2008 hubo un $36.79 \%$ de conciliaciones con acuerdo respecto de las solicitudes, a diferencia de un promedio de $6.94 \%$ entre los años 2009 y 2012, lo cual se traduce en una reducción del 81.14 \%, 5 veces menos, en el porcentaje de conciliaciones con acuerdo respecto de las solicitudes de conciliación. En conclusión, la introducción del requisito de procedibilidad de la conciliación supuso una reducción significativa en el índice de acuerdos como porcentajes de las solicitudes de conciliación, concretamente, mientras que previa a la ley 1285 de 2009, la conciliación fracasaba en 63 de cada 100 intentos, posterior a la misma ley, la conciliación fracasa en 93 de cada 100 intentos. (Díaz y García, 2014).

Estas cifras sustentan la hipótesis de este trabajo de que la conciliación en la acción de nulidad y restablecimiento del derecho no es un mecanismo idóneo, porque si fuera verdad que la conciliación coopera a que las partes encuentren una solución a sus diferencias, entonces, ¿cómo se explica el gran número de solicitudes en las que no se obtiene ningún tipo de acuerdo?

De ahí que no son claras las razones por las cuales no se llega a un acuerdo conciliatorio; y, como argumenta Guerra (2014), "quizás sea por causas normativas o de actitud entre las partes, ya que se sostiene que a los servidores públicos no les gusta conciliar, por temor a comprometer recursos del erario, y prefieren mejor que el juez emita sentencia” (p. 23 ).

A continuación se verán lo cuadros estadísticos que revelan las cifras relacionadas con las audiencias de conciliación surtidas en los despachos administrativos de la Procuraduría General de la Nación y sus resultados.

Tabla 1. Resultados audiencias de conciliación.

\begin{tabular}{|l|c|c|c|}
\hline Audiencias & 2013 & 2014 & 2015 \\
\hline Con acuerdos & 5.663 & 10.676 & 6.803 \\
\hline Radicadas con trámite efectivo & 63.291 & 65.568 & 50.884 \\
\hline Sin acuerdo & 51.354 & 54.103 & 43.203 \\
\hline
\end{tabular}

Fuente: elaboración propia. 
Figura 1. Conciliaciones extrajudiciales en materia contencioso administrativa.

Número de conciliaciones solicitadas

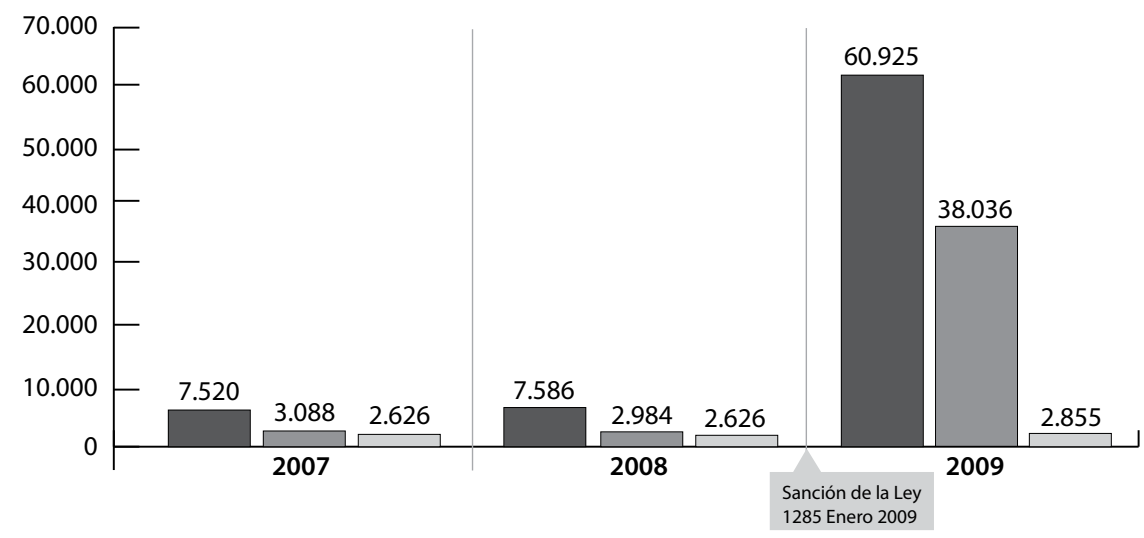

\begin{tabular}{|l|c|c|c|}
\hline Cuantía pretendida & 224.489 .604 .620 & 424.472 .429 .118 & 360.634 .070 .361 \\
\hline Cuantía acordada & 147.773 .351 .243 & 341.757 .332 .109 & 160.860 .209 .028 \\
\hline Ahorro patrimonial & 78.716 .253 .377 & 82.715 .097 .019 & 199.773 .861 .333 \\
\hline $\begin{array}{l}\text { Variación anual del incremento del ahorro } \\
\text { patrimonial }\end{array}$ & & $5 \%$ & $142 \%$ \\
\hline
\end{tabular}

Fuente: Procuraduría General de la Nación, Procuraduría Primera Delegada ante el Consejo de Estado, 2010. Cálculos: Corporación Excelencia en la Justicia, 2010.

Figura 2. Numero de conciliaciones del 2009 al 2014.

$\square$ Emitidas $\square$ Con acuerdo $\square$ sin acuerdo

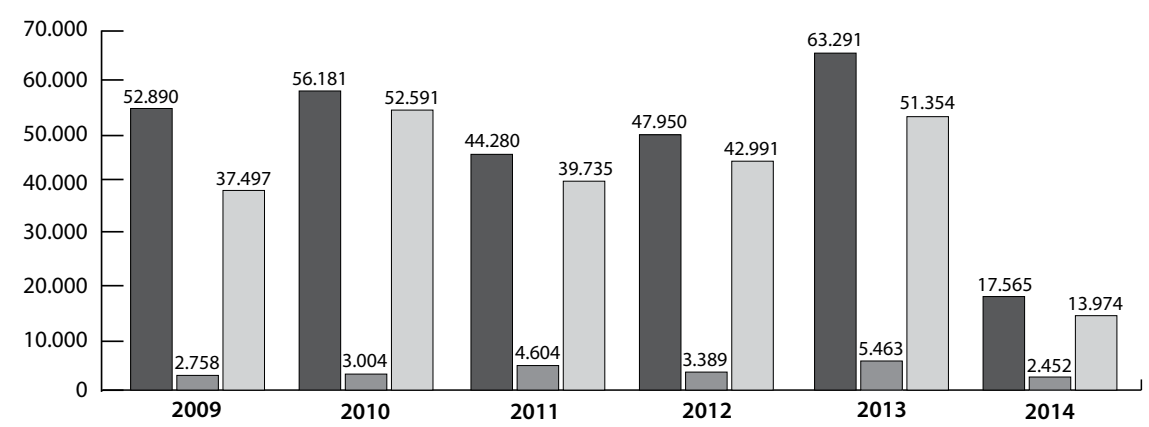

Fuente: Guerra, 2014. 
Figura 3. Comportamiento de las conciliaciones extrajudiciales y judiciales.

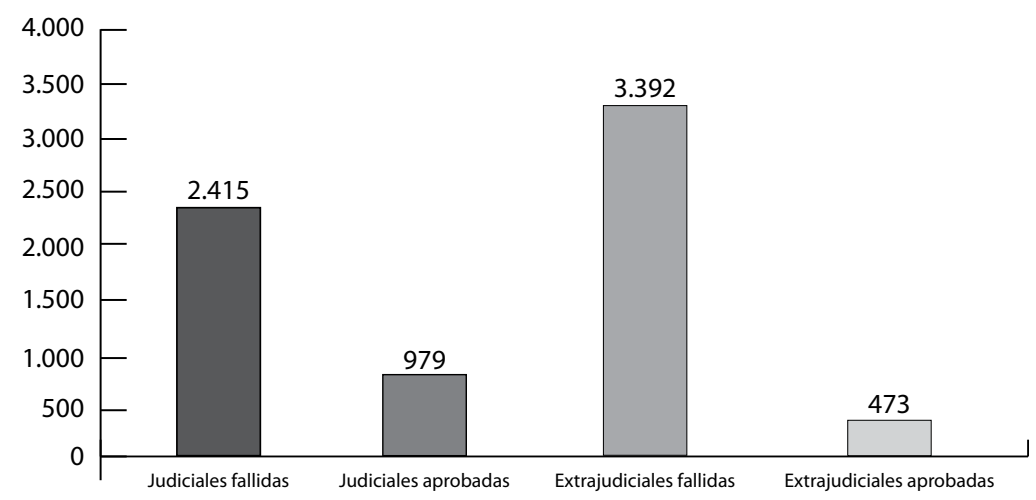

Fuente: Alarcón y Forero, 2014.

Los datos anteriores reflejan que pese a que la doctrina, la jurisprudencia, el congreso y el Gobierno han insistido en que la conciliación contribuye con el propósito de descongestionar los despachos judiciales, no obstante, la realidad es otra, pues las cifras de la Procuraduría desvirtúan este argumento pues "el ingreso de procesos judiciales a la jurisdicción contenciosa administrativa aumentó considerablemente, ya que dicho ingreso pasó de 67.762 procesos en el 2009 a 163.256 procesos en el 2012, lo que significa un incremento del 140.93 \%" (Díaz, 2014).

De lo expuesto ut supra, se colige que la conciliación administrativa no ha sido eficaz en conseguir su objetivo principal, y es por ello que se apoya el argumento de Guerra (2014), quien afirma que:

Lo ideal es que cuando se utilicen mecanismos que tengan la esencia de agilizar procesos, lo más lógico y razonable es que tales funcionen realmente y no se constituyan en procedimientos intrascendentes, entorpecedores y sobre todo desgastantes, ubicándose lejos de cumplir las expectativas para los cuales fueron erigidos. Esto sucede con la conciliación extrajudicial en lo contencioso administrativo, puesto que no está cumpliendo su cometido, por el contrario se ha convertido en un requisito que limita el acceso a la justicia (p. 9).

Lo anterior pone de relieve que la conciliación administrativa no ha logrado sus propósitos, tan es así que hay una propuesta radicada en la Cámara de 
Representantes encaminada a que se elimine la conciliación como requisito de procedibilidad. Los motivos de la reforma que se pretende en el congreso son los siguientes:

En primer lugar, los funcionarios que representan al Estado en los pleitos que se surten en su contra, por regla general, optan por no conciliar. Otro de los motivos planteados dentro de la propuesta es que las entidades o instituciones demandadas no cuentan con los recursos suficientes, prefiriendo posponer el momento del pago, la conclusión de los creadores de la iniciativa es que el modelo de conciliación contencioso administrativa, tal y como funciona en la actualidad, contrario a incentivar la solución pacífica de conflictos y a propender porque los jueces conozcan los casos que ameriten su estudio, está representando una verdadera traba para que los ciudadanos puedan acceder a la administración de justicia (Ámbito Jurídico, 2016).

Lo anterior encuentra sustento en el estudio que hizo el Departamento Nacional de Planeación en el año 2015, en el cual se constató que:

En el periodo 2002-2014 se han atendido a través del mecanismo de la conciliación un poco más de 940.000 casos, con un promedio anual de 72.400 casos atendidos, y con una tendencia creciente, es posible concluir que la conciliación no ha ayudado a resolver la congestión en el sentido que se le haya quitado carga a los jueces que alegan tenerla en exceso para que sea resuelta a través de este mecanismo.

Es así como hasta el momento la conciliación no ha respondido a los conflictos que se presentan en la población, pues su regulación no ha obedecido a un estudio de las necesidades jurídicas que se presentan y que pueden ser susceptibles de conciliación. En Colombia ha faltado promover una cultura de solución de conflictos por medio de los MASC. En muchos casos, especialmente en materia contencioso administrativa, la conciliación se ha entendido como un simple trámite y se realiza únicamente con el objeto de evacuar el requisito de procedibilidad para acudir al juez, sin intención de conciliar (DNP, 2015).

En aras de demostrar lo planteado en la hipótesis de este artículo, es decir que la conciliación no es un medio idóneo para garantizar el acceso a la administración de justicia, es necesario citar las conclusiones del Análisis Conceptual del Sistema Nacional de Conciliación en Colombia en sus 25 años, en cual se establece que: 
Una vez revisadas las estadísticas aportadas por diferentes entidades sobre el uso de la conciliación, se concluye que la conciliación no ha cumplido con las finalidades para las cuales fue instaurada. Es decir no ha contribuido a la desjudicialización y descongestión de los despachos judiciales, ya que el número de demandas presentadas supera ampliamente los trámites de conciliación adelantadas y tampoco constituye un mecanismo de acceso a la justicia, ya que los ciudadanos prefieren no tomar medidas sobre el conflicto y si la hacen recurren preferiblemente a una autoridad. Solo una pequeña proporción de la población con conflictos acude a la conciliación como mecanismos para resolverlos (Departamento Nacional de Planeación, 2015).

\section{Conclusiones}

1. La conciliación prejudicial en materia contencioso administrativa no es un mecanismo idóneo para lograr la descongestión judicial según las estadísticas de la Procuraduría General de la Nación, que confirman que son ínfimos los asuntos que terminan con acuerdo conciliatorio.

2. La conciliación prejudicial ha obstaculizado el efectivo acceso a la administración de justicia de los administrados y ha conculcado caros derechos fundamentales como el debido proceso y el trabajo, tal como se evidencia en el expediente 42202-02 de 2003, casos en los cuales los operadores judiciales se declararon inhibidos para desatar la litis, por no haberse efectuado conciliación prejudicial de un acto administrativo inoponible a los afectados por haberse pretermitido la notificación; lo cual pone de relieve que la conciliación ha generado un exceso de formalismo y rigor que dificulta a los ciudadanos el acceso efectivo a la administración de justicia, violándose así el principio consagrado en el artículo 228 de la C.P. "sobre la prevalencia del derecho sustancial sobre el formal".

3. La conciliación administrativa prejudicial no ha sido eficaz en su propósito de descongestión judicial, y es un mecanismo entorpecedor del acceso a la administración de justicia, dándose la necesidad de una iniciativa de reforma legal para eliminar la conciliación, porque según las conclusiones del Informe del Departamento Nacional de Planeación, se determinó que los funcionarios estatales por regla general deciden no conciliar, sin que las entidades estatales demandadas dispongan de presupuesto suficiente para conciliar. 
4. No resulta justo ni equitativo para la ciudadanía que los operadores jurídicos emitan sentencias inhibitorias absteniéndose de decidir de fondo los diferentes litigios con el pretexto de que no se agotó el pluricitado requisito de la conciliación prejudicial, cuando se evidencia que, por regla general, el Estado no concilia, y que los casos en que lo hace son ínfimos, como se demuestra con las estadísticas proporcionadas por el Consejo Superior de la Judicatura y la Procuraduría General de la Nación, yendo en contravía de la Constitución, sacrificando el derecho sustancial sobre el procedimental, pues muchos operadores judiciales ven como obstáculos poner en práctica este principio bajo una falsa eficacia (cuantitativa), razón por la que sus actuaciones denotan una flagrante denegación de justicia.

5. La conciliación prejudicial por ser inocua para el acceso a la administración de justicia debe ser eliminada con la implementación de mecanismos que faciliten el acceso de la ciudadanía a la justicia para que se garantice el respeto de sus derechos sin ritualismos que riñen con los principios de la Carta Política, en especial el que consagra a Colombia como un "Estado Social de Derecho".

\section{Referencias}

Alarcón, O., y Forero, H. (2014). Inoperancia de la conciliación extrajudicial en la jurisdicción contencioso administrativa aplicada a la Policía Nacional. Bogotá: Universidad Militar Nueva Granada. Recuperado de http://repository.unimilitar.edu.co/bitstream/10654/12140/1/ TRABAJO\%20DE\%20GRADO\%20UMNG\%20ESPECIALIZACI\%C3\%93N\%20 DERECHO\%20ADMINISTRATIVO.pdf

Ámbito Jurídico. (2016). Eliminarían conciliación extrajudicial como requisito de procedibilidad. Recuperado de https://www.ambitojuridico.com/BancoConocimiento/AdministracionPublica/eliminarian-conciliacion-extrajudicial-como-requisito-de-procedibilidad-enasuntos-contencioso-admin.cshtml

Berlín, L. (1999). Conciliación Administrativa. Bogotá: Procuraduría General de la Nación. Recuperado de https://www.procuraduria.gov.co/portal/media/file/Cartilla_La_Conciliacion_PDCA.pdf

Bermejo, J. (2015). La conciliación prejudicial contenciosa administrativa. Jurídicas CUC, 11(1), 107-134. Bogotá: Universidad Libre. Recuperado de https://dialnet.unirioja.es/ descarga/articulo/5162526.pdf 
Casares, J. (2012). Diccionario ideológico de la lengua española. Barcelona: Casa del Libro.

Cerra, E. (2011). Conciliación en derecho administrativo. Advocatus, (16), 47-58. Barranquilla: Universidad Libre. Recuperado de http://www.unilibrebaq.edu.co/ojsinvestigacion/ index.php/advocatus/article/viewFile/162/155

Corporación Excelencia en Justicia. (27 de septiembre de 2012). Conciliaciones extrajudiciales en materia contenciosa administrativa. Recuperado de http://www.cej.org.co/index. $\mathrm{php} /$ justiciometros3/3436-evolucion-de-conciliaciones-extrajudiciales-en-materiacontencioso-administrativa

Congreso de Colombia. (18 de enero de 2011). Disposiciones generales. [Ley 1437]. DO: 47.956.

Congreso de Colombia. (5 de enero de 2001). Normas generales aplicables a la conciliación. [Ley 640]. DO: 44.303.

Corte Constitucional de Colombia. (17 de marzo de 1999). Conciliación-Naturaleza. Sentencia C-160/99. [M.P. Martha Sáchica de Moncaleano].

Corte Constitucional de Colombia. (7 de marzo de 1999). Derecho de acceso a la justicia. Sentencia C-163. [M.P. Alejandro Martinez Caballero]

Corte Constitucional de Colombia. (1 de diciembre de 1999). Principio de publicidad, rige la actividad del Estado. Sentencia C-957/99. [M.P. Álvaro Tafur Vargas].

Corte Constitucional de Colombia. (15 de noviembre de 2001). Cosa juzgada constitucional, conciliación extrajudicialen materia laboral. Sentencia C-1195. [M.P. Rodrigo Uprimny Yepes].

Corte Constitucional de Colombia. (17 de abril de 2013). Improcedencia toda vez que la demanda si plantea un cargo mínimo de inconstitucionalidad. Sentencia C-222. [M.P. Alexei Julio Estrada].

Corte Constitucional de Colombia. (8 de septiembre de 1998). Acción de tutela. Alcance. Sentencia T-476. [M.P. Fabio Morón Díaz].

Corte Constitucional de Colombia. (9 de mayo de 2013). Derecho de acceso a la información pública. Contenido y alcance. Sentencia C-274. [M.P. María Victoria Calle].

Corte Constitucional de Colombia. (17 de juno de 1993). Jurado de derecho. Naturaleza. Sentencia C-226. [M.P. Alejandro Martín Caballero].

Consejo de Estado. (1999). Sección tercera, auto 30 de septiembre. [C.P. Ricardo Hoyos].

Consejo de Estado. (2012). Sección segunda, 2 de agosto. [C.P. Víctor Alvarado Ardila].

Couture, E. (1960). Vocabulario jurídico. Sexta impresión. Argentina: Ediciones de Palma.

Departamento Nacional de Planeación. (2015). Análisis conceptual del sistema de conciliación en Colombia en sus 25 años. Construyendo diálogo y paz para el futuro. Bogotá. Recuperado de https://colaboracion.dnp.gov.co/CDT/Prensa/Publicaciones/13\%2025\%20 a\%C3\%B1os\%20del\%20Sistema\%20Nacional\%20de\%20Conciliaci\%C3\%B3n.pdf 
Díaz, D., y García, A. (2014). La conciliación extrajudicial como requisito de procedibilidad y sus verdaderos efectos. Revista Con-texto de Derecho y Economía, 41, (pp. 143-176). Bogotá. Recuperado de http://revistas.uexternado.edu.co/index.php/contexto/article/ view/3856

García, F. (2008). La conciliación administrativa. Bogotá: Grupo Editorial Ibáñez.

Gil, J. (2011). La conciliación extrajudicial y la amigable composición. Bogotá: Editorial Temis. Giraldo J. (2004). Mecanismos alternativos de solución de conflictos. Bogotá: Librería Ediciones del Profesional.

González, S. (2010). Conciliación extrajudicial en asuntos contencioso administrativos: hacia nuevo paradigma. Revista Digital de Derecho Administrativo, 4, (pp. 57-76). Bogotá. Recuperado de https://dialnet.unirioja.es/descarga/articulo/5137221.pdf

Guerra, O. (2014). Ineficacia de la conciliación extrajudicial. Artículo para optar al título de especialista en Derecho Administrativo. Bogotá: Universidad Militar Nueva Granada. Recuperado de http://unimilitar-dspace.metabiblioteca.org/handle/10654/12577?locale=es

Henao, J. (1998). La conciliación en el derecho administrativo. Bogotá: Ministerio de Justicia.

Henao, J. (1996). La conciliación en el derecho administrativo. Bogotá: Interconed.

Hernández, A. (2005). La conciliación extrajudicial en derecho como requisito de procedibilidad. Bogotá: Leyer.

Hoyos, C. (2005). La conciliación, un modelo bioético hermenéutico. Medellín: Señal Editora. Informe al Congreso de la Republica (2013). Sala Administrativa del Consejo Superior de la Judicatura. Recuperado de http://www.comisionprimerasenado.com/informes -a-la-comision/299-estado-de-la-administracion-de-justicia-ano-2013/file

Peña, H. (2014). La conciliación como mecanismo de resolución de conflictos. Recuperado de http:// www.academia.edu/8936069/La_Conciliaci\%C3\%B3n_como_Resoluci\%C3\%B3n_de_ Conflictos_Parte_I_-_La_conciliaci\%C3\%B3n_no_descongestiona_la_justicia

Procuraduría General de la Nación. (2016). Respuesta al derecho de petición incoado por la estudiante Gloria Torres. Bogotá.

Sabino, C. (1992). El proceso de investigación. Caracas: McGraw-Hill.

Saidiza, H., y Carvajal, J. (2016, enero-junio). Nuevas lógicas autoritarias y crisis del estado de derecho en Colombia. Un análisis de la legislación penal de emergencia inscrita en el manejo jurídico de la protesta social. Revista Verba Iuris, 35, (pp. 13-39).

Toscano, F. (2013). Aproximación conceptual al acceso efectivo a la administración de justicia. Revista de Derecho Privado, 24. Bogotá: Universidad Externado de Colombia. Recuperado de http://revistas.uexternado.edu.co/index.php/derpri/article/view/3486/3472 